\title{
GeoQuest Project Computer Class Role Playing Game as Innovative Teaching Methodology to Foster STEAM Education
}

\author{
Sabina Maraffi ${ }^{1}$ and Francesco Maria Sacerdoti ${ }^{2}$ \\ 1. School of Science and Technology, Department of Geology, University of Camerino, Camerino (MC) 63032, Italy \\ 2. e-voluzione s.r.l., Via Diocleziano 107, Naples 80125, Italy
}

\begin{abstract}
GeoQuest Project is the design of a new teaching and learning technology based on Computer Class Role Playing Games (RPG) to teach Earth Science in a STEAM educational approach. It ensures interdisciplinarity, multilingual approach (CLIL compliance) and interactive activities in classrooms. This educational game uses students' personal tablets and smartphones to interact with the game, with a system more comprehensible and funny for young people compared to traditional methodologies. Students are bringing "in situation" by the adventure, so teachers can get a rigorous assessment of their skills. The Game includes several adventure paths, suitable for different age students. They are focused on scientific topics, humanities, hands-on activities in interdisciplinary way. If used conditions do not allow practical or laboratorial activities provided by the game, players can see some videos to understand the activities. Experimental results were outstanding: the RPG appreciation is in agreement with the experiments outcome. This work experience gets excellent feedbacks by teachers, in terms of efficacy of this new teaching methodology and of results achieving.
\end{abstract}

Key words: Science education, education game, education technology, teaching methodologies, STEAM, STEM, earth science.

\begin{tabular}{|c|c|}
\hline CLIL & Content Language Integrated Learning \\
\hline IBL & Inquiry-Based Learning \\
\hline IBSE & Inquiry-Based Science Education \\
\hline IESO & International Olympiads of Earth Sciences \\
\hline IGEO & International Geoscience Education Organisation \\
\hline IWB & Interactive Whiteboard \\
\hline OCSE & Italian name of OECD \\
\hline OECD & $\begin{array}{l}\text { Organisation for Economic Co-operation and } \\
\text { Development }\end{array}$ \\
\hline RPG & Role Playing Game \\
\hline SEN & Special Educational Needs \\
\hline STEAM & $\begin{array}{l}\text { Science, Technology, Engineering, Mathematics, } \\
\text { combined with Arts }\end{array}$ \\
\hline STEM & Science, Technology, Engineering, Mathematics \\
\hline SSH & Social Sciences \& Humanities \\
\hline PPT & $\begin{array}{l}\text { Digital presentation } \\
\text { (i.e. Power Point presentation file) }\end{array}$ \\
\hline
\end{tabular}

\section{Introduction}

This new technology is designed for deeper

Corresponding author: Sabina Maraffi, Ph.D. candidate, main research field: science education. learning of Science, Technology, Engineering, Mathematics, combined with Arts (STEAM) and Social Sciences \& Humanities (SSH), improving the innovation and creative capacities of learners and supporting the new role of teacher as a coach of the learner. It's naturally a mixed reality learning environment, giving the students the feel "to be IN adventure environment". The student interaction is realised by using new interfaces: students use their own tablet or smartphone to interact with the game.

In recent years, many studies have highlighted an alarming decline in young people's interest for key science studies and mathematics [1-4]. Despite the numerous projects and actions that are being implemented to reverse this trend, the signs of improvement are still modest. There is obviously a need to prepare young people for a future that will require high scientific knowledge and a good understanding of technology [5]. 


\subsection{Science Education}

In 2006, Michel Rocard, a member of the European Parliament and former Prime Minister of France, drawn attention on the decline in the interest of young people in science and mathematics that could lead to decline in long-term innovation capacity of Europe and in quality of scientific research [6]. The world general trend of worsening is shown in Fig. 1.

There is firm evidence which indicates a connection between attitudes towards science and the way science is taught [5]. In 2008, it emerged that in Italian schools, laboratory teaching has a marginal presence in science education at all school levels, as indicated in the research conducted by a working group established by the Italian Education Ministry. The report indicated that the absence of laboratory activities was primarily due to a lack of or poorly equipped laboratories, as well as the difficulties of teachers in doing experimentations with students. Moreover, teaching Earth Science in Italian secondary schools is more challenging than teaching other science subjects since it meets with little interest and is perceived as marginal compared with other school subjects: contents are rote-learnt and processes remain substantially abstract and perceived as unconnected with reality $[6,7]$.

The existing scientific literature, in the field of Earth Sciences coming from several universities distributed in the world, is however, primarily focused on the development of content, on research and new fields of discovery and investigation, more than on research of new and effective educational approaches. In fact, the literature rarely considers the education approach, the need to make the acquired contents and new discoveries easier to be understood by a non-specialist public. As a consequence, this lack produces an absence of elaboration and of abstraction of the discipline itself, not focused on a disciplinary epistemology and weakly comparable with other sciences [8].

In Fig. 2 [8], there is a comparison between the results obtained for STEM and the public spending on education and training. It can be seen that the best results are obtained by those countries with the highest public investment in education and training. However, the best results are obtained where there is a high attention to culture and education, in particular, socio-economical attention to STEM.

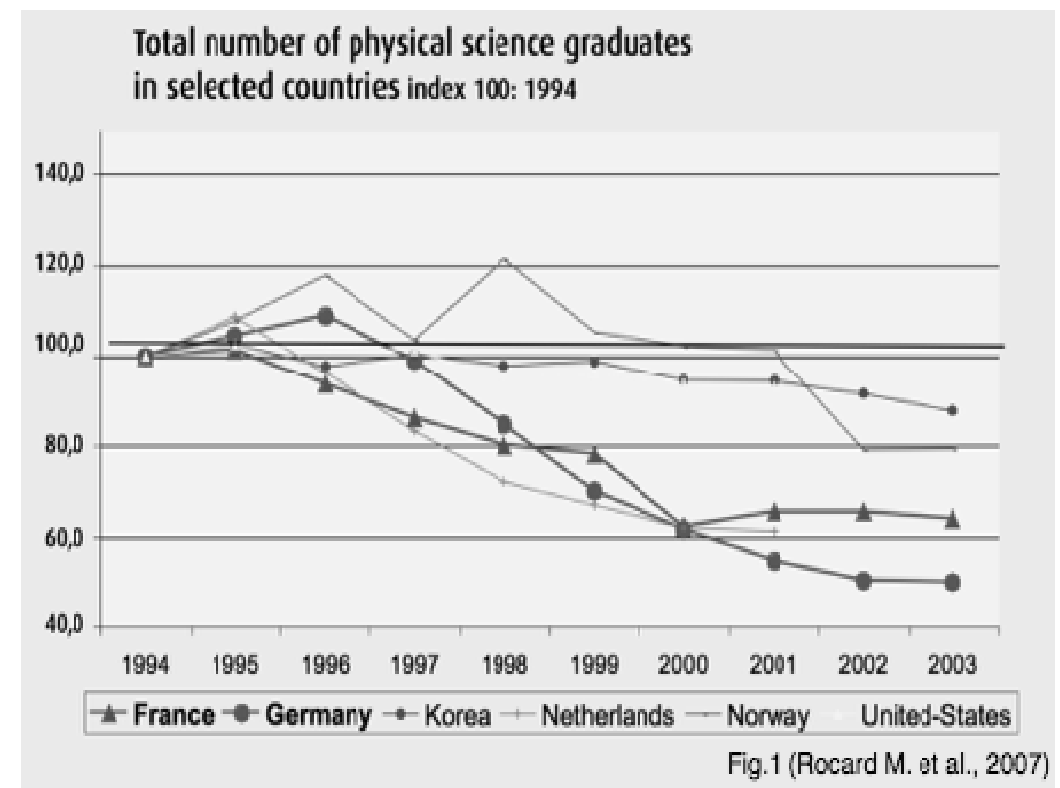

Fig. 1 The decline in interest of young people in science and mathematicscould lead to the decline in long-term innovation capacity of Europe and in the quality of scientific research. 


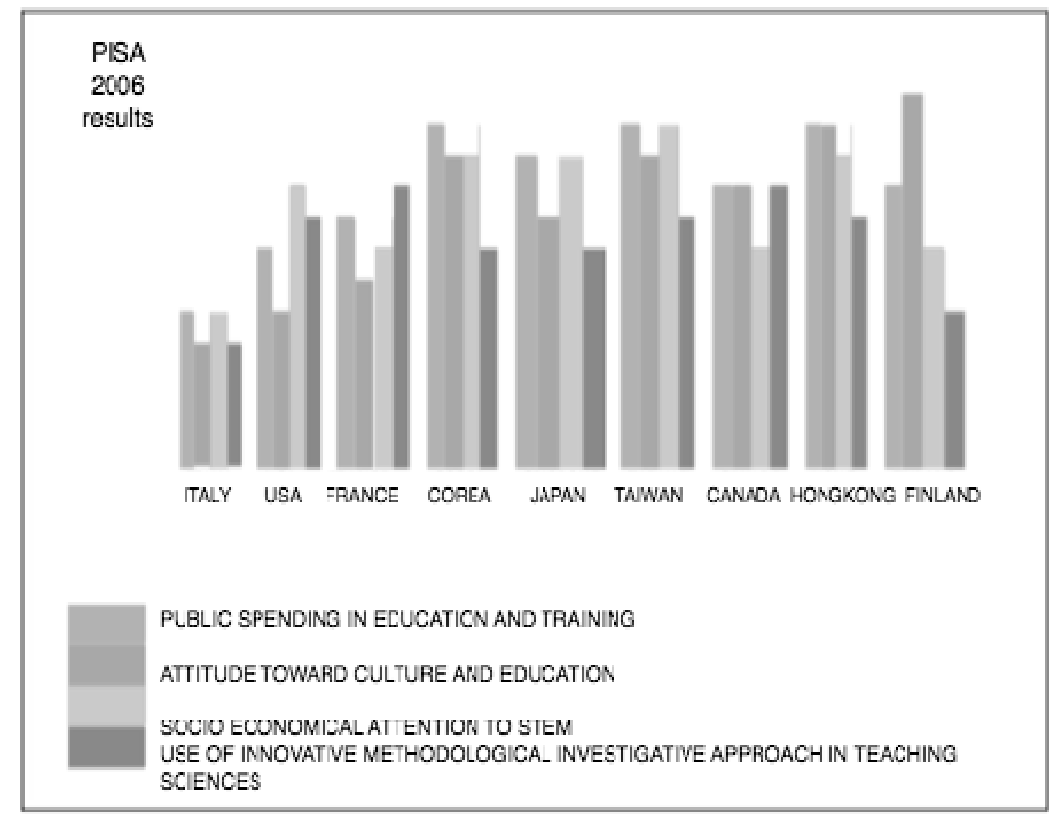

Fig. 2 Interesting is that the best results are obtained where there is a high attention to culture and education and in particular, socio-economical attention to STEM.

\subsection{Science Teaching}

Eurydice [9] report points out that "there is substantial variation in the status and prestige of science teachers across Europe. The research suggests that it is the quality of the teacher that is the major determinant of student engagement with science. Recruiting and retaining the highest calibre teachers of science is, therefore, a critical factor in improving and sustaining the quality of school science education." There were analysed some experiences [8]:

- IESO (International Olympiads of Earth Sciences);

- IGEO (International Geoscience Education Organisation).

The results highlight that the most important factors for success in this type of competitions seems to be:

- importance of socio-economical attention to STEM. Particularly the interest addressed by institutions, companies and families to scientific culture and its development by schools which evidently led to a greater involvement of students in the international test;

- teachers training in universities, training courses in professional development for teachers on methodology (e.g. Taiwan, USA), different methodologies for the development of operational skills, and in particular the support to teachers' work;

- internships organised for selected students;

- much less important for being the use of innovative methodological approaches. Teachers with high professionalism or involved in active teaching-learning approaches, seem to be the best candidate to increase teaching outcomes. Teacher support should be a priority to obtain good results [8].

\subsection{Europe Engaging}

As stated on the website [10], the European Union is working hard to move beyond the crisis to create the conditions for a more competitive economy and higher employment rate.

The Europe 2020 strategy is focused on three mutually reinforcing priorities:

- Smart growth: developing an economy based on knowledge and innovation.

- Sustainable growth: promoting a more resource efficient, greener and more competitive economy.

- Inclusive growth: fostering a high-employment economy delivering social and territorial cohesion. 
Smart growth promotes:

(1) education: encouraging people to learn, study and update their skills;

(2) research/innovation: creating new products/services that generate growth and jobs to help address social challenges;

(3) digital society: using information and communication technologies.

Sustainable growth means:

(1) building a more competitive low-carbon economy that makes efficient, sustainable use of resources;

(2) protecting the environment, reducing emissions and preventing biodiversity loss;

(3) capitalising on Europe's leadership in developing new green technologies and production methods;

(4) introducing efficient smart electricity grids;

(5) harnessing EU-scale networks to give our businesses an additional competitive advantage;

(6) improving the business environment, in particular for SMEs;

(7) helping consumers make well-informed choices.

Inclusive growth focuses on:

(1) raising Europe's employment rate-more and better jobs, especially for women, young people and older workers;

(2) helping people of all ages to anticipate and manage change through investment in skills \& training ;

(3) modernising labour markets and welfare systems;

(4) ensuring the benefits of growth reach all parts of the EU.

\subsubsection{Environment Management}

Activities in this Challenge will help increase European competitiveness, raw materials security and improve well-being. At the same time, they will assure environmental integrity, resilience and sustainability.

To ensure EU added value and given the transnational and global nature of the climate and the environment, their scale and complexity, and the international dimension of the raw materials supply chain, activities have to be carried out at and beyond the Union level. Reducing resource use and environmental impacts, whilst increasing competitiveness, will require a decisive societal and technological transition to an economy based on a sustainable relationship between nature and human well-being.

Innovation in these fields will provide opportunities for growth and jobs, as well as innovative options involving science, technology including of ICT, the economy, society, policy and governance.

Research and innovation will cover the following broad lines of activities:

- Climate Action-Informed decisions for a climate-resilient low-carbon society;

- Cultural Heritage-Engaging a new cultural heritage agenda for economic growth;

- Earth Observations-Crucial info on climate, energy, natural hazards and other societal challenge;

- Nature-Based Solutions-Providing viable solutions of natural ecosystems;

- Systemic Eco-Innovation-Generating and sharing economic and environmental benefits [11].

\subsubsection{Education Technology}

In most European countries, and also in Italy [12], science teaching methods are still mostly deductive, which means that the presentation of concepts come first and are followed by examples of applications, while experiments are confirmative mainly as a teacher's demonstration. This approach is also referred to as top-down transmission [5].

On the contrary, the inductive approach gives more space to observation, experimentation and to the construction by the children of their own knowledge whereas the teacher has the role of facilitator of learning. This is also described as a bottom-up approach [5]. The terminology changed over time and also the concepts refined. Today the inductive 
approach is most often referred to as Inquiry-Based Learning (IBL) or, in Europe, Inquiry-Based Science Education (IBSE) [5].

In the official definition of the eight key competences on European Parliament and Council Recommendation of 18 December 2006 (2006/962/EC), the competence in science refers to the ability and willingness to use the body of knowledge and methodologies held to explain the world around us to identify questions and to draw conclusions that are based on proven facts.

In 2015, the definition of Scientific Literacy [13] is changed to best fitting last instances: "Scientific Literacy is the ability to engage with science-related issues and with the ideas of science, as a reflective citizen".

A scientifically literate person is willing to engage in reasoned discourse about science and technology which requires the competencies to:

(1) explain phenomena scientifically: recognise, offer and evaluate explanations for a range of natural and technological phenomena;

(2) evaluate and design scientific enquiry: describe and appraise scientific investigations and propose ways of addressing questions scientifically;

(3) interpret data and evidence scientifically: analyse and evaluate data, claims and arguments in a variety of representations and draw appropriate scientific conclusions.

Many on-going initiatives in Europe actively contribute to the renewal of science education. Nevertheless, they are often small-scale and do not actively take advantage of European support measures for dissemination and integration.

Priority given to initiatives that include a large diversity of practices in science teaching to respond to the diverse needs of children: problem based inquiry process, hands-on/minds-on activities, team-work, independent work on open-ended questions, trans-disciplinary activities, showing relevance of science content [5].

\subsubsection{Earth Sciences at School}

It was very hard to find useful bibliography, due to low interest of the educational community towards Earth Sciences as well as low interest of the geosciences scientific community towards education [8]. Some reasons for this lack of interest is undoubtedly the cultural background of teachers, which in most cases are biologists and not geologists.

In addition, Earth Sciences provide many interdisciplinary connections with physics, chemistry and geography, perceived by many teachers as non-specialistic topics of their profession.

In Italy, a recent survey [14] shows:

- poor compliance to Ministry guidelines;

- scarce use of laboratory and fieldwork activities;

- tendency to follow old teaching habits practices as well as high prevalence of theoretical teaching.

Finally, at least in Italy, the social pressure of the stakeholders is given to the life sciences, as an integral part of the preliminary selective tests for admission to university courses. Furthermore, environmental protection is of high priority in European programming. Italy is a country affected by geological emergencies of various types (seismic, hydrogeological and volcanic) and should be the leading country in the reappraisal and consideration of Earth Sciences.

\section{Material and Methods}

In addition to structural education and training system reforms, there has been substantial methodology changes [15] based on:

- Use of Information and CommunicationsTechnologies (ICT);

- Laboratory Didactics;

- Cooperative Learning;

- Group Investigation;

- Peer Tutoring;

- Peer Collaboration.

\subsection{Innovative Teaching}

Educational technology is based on the use of 
language closer to pupils to improve the teaching/learning process. Transferring online traditional teaching practices does not produce an improvement in learning, as well as the digital conversion of the transmission model of knowledge does not generate educational innovation (Fig. 8).

The lesson conducted using a digital presentation (PPT) is practically a frontal lesson; the simple use of Interactive Whiteboard (IWB) which can not guarantee education does not remain merely transmissive. To go beyond the traditional teaching is not sufficient with the use of digital technology and the web, but it's necessary to create a learning environment focused on "communication" with active interaction among all members of the educational community so that "everyone can give according his abilities and receive according to his needs" [16].

It's necessary to overcome the transmissive teaching with an approach not deductive, but inductive, that manages to combine laboratory activities, cooperative learning, peer education, using ICT as a tool to expand the potential of student investigation in inquiry process.

\subsubsection{Teacher Role}

About teaching and education, De Benedetti [17] claims that competence in school is developed as a task dilated over time, so that the students, with their different intelligences and abilities find all learning conditions.

Teacher, as a trainer, supports and models student's behaviour with examples and suggestions. Teacher enables the development of metacognition, provides information as positive feed-back, facilitates in students' construction process of knowing how to act in each situation, and compares learning ways of other students.

The positive experience of the Flipped Classroom ensured us that it is not necessary that the class activity follows the theory: the class activity may instead be a stimulus for the investigation by the students, led by the teacher.

\subsubsection{Inquiry Based Science Education (IBSE)}

Inquiry Based Science Educationhas proved its efficacy at both primary and secondary levels in increasing children's and students' interest and attainments levels while at the same time stimulating teacher motivation. IBSE is effective with all kinds of students from the weakest to the most capable and is fully compatible with excellence ambition.

Moreover, IBSE is beneficial to promoting girls' interest and participation in science activities. Finally, IBSE and traditional deductive approaches are not mutually exclusive and they should be combined in any science classroom to accommodate different mindsets and age-group preferences [5]. From a depth experience of teaching with IBSE approach, however, it emerges some points of weakness: teachers surveyed agree that the implementation of educational activities with IBSE methodology requires a massive planning stage, prolonged times and a variety of tools not always easy available.

In short, while IBSE may improve the effectiveness of teaching, it often worsens the workload of teachers.

\subsection{Teaching with the Game}

In the obligatory school levels, like in the longlife learning, the game is an essential element and activity for the development of everybody's personality, especially in the perspective of learning to learn (Key Skills). "Learning to learn" is recognised as a meta-skill which evolves with the student and becomes the thread that guides him to a successful assumption of responsibility for its own learning process. The most effective mode of realisation of metacognitive teaching, it seems to be the self-regulating approach, in which students are helped in the process of recognition of the skills necessary for learning tasks and they are encouraged for the choice and for the most productive application of appropriate learning strategies [18].

Until now, serious games are a significant step forward compared to many ways of using ICT in education, which, as it happens with the traditional 
e-learning, have often repeated the transmissive model, providing content with rich combinations of texts, pictures and possibly video and audio, but with limited possibilities for effective interaction with the teacher and with other students [19].

\subsubsection{Role Playing Game}

In classical role playing game you play a character, stay around a table and the tale is shared.

This last aspect is the most important to distinguish the role play by any other computer game, including those which make use of avatars and virtual world. Even in them, in fact, the player carries on his own quest alone [20]. The most current literature about this subject [21] highlights the following important aspects of the role play game in the educational field: Motivation, Cooperation, Identification, Narration, Exploration, Review and Planning.

\subsubsection{Computer Game}

Computerised games are a formidable gym to exercise the "core capacities" involved in cognitive enhancement activities, because reaching the game objectives calls for the simultaneous and coordinated application of a large number of mental processes such as visual attention, processing visus-space, executive function, learning ability and memory, in addition to experiment with their coordinated use in the situation [22].

A key role consists of mediation. Among the main forms of mediation involved in computer game, there is the automatic feedback: it refers to the error handling strategies proposed in the game. While in school activities, the error is a potential source of frustration to be avoided at any costs, in the game it is a normal part of experience. After the error you can restart without any consequence, on the contrary, having learned something [23].

\subsection{STEAM Education}

Daily teachers live on their skin than they change the learning ability of the children and perceive a world of constant and rapid change. The school task would be to contribute to the improvement of society and not to restore a 'status quo': this would be enough to persuade the school to rethink itself and to traditional teaching strictly focused on the disciplines to embrace more cross paths that can convey the reasons guys, tools and methods for continuous training [24].

STEAM is an educational approach that uses Science, Technology, Engineering, Arts and Mathematics (STEAM) as access points for guiding student inquiry, dialogue, and critical thinking. The end results are students who take thoughtful risks, engage in experiential learning, persist in problem-solving, embrace collaboration, and work through the creative process.

Multidisciplinary approach requires STEAM and Social Sciences \& Humanities (SSH) cross correlation; this kind of approach is increasingly required in the new teaching frontiers school: it is not simply the "connection" between scientific and historical, literary, mythological topics through interesting and captivating textual references.

With the international surveys which have highlighted the gaps in students' knowledge, skills and abilities, it was set up a proper definition of literacy: "reading literacy is understanding, using and reflecting on written texts, in order to achieve one's goals, to develop one's knowledge and potential and to participate in society" [3]. Research has shown us that it is possible to repeat the text's content, even well, but that this doesn't imply at all that the meaning absorption happened, the true understanding of text [15]. At the base of correct understanding of a text, there is therefore the ability to build a semantic representation coherent and well-formed [25-27].

\subsection{GeoQuest Project}

GeoQuest is the Game Project to realise Class Adventures RPG to be played by the whole class with a single story to be lived all together. The first realised adventures are on Earth Sciences, Physics, Chemistry, 
Math, History, Literature, Myth and more.

The adventures are multidisciplinary and multilanguage (Fig. 3). The plots are designed for deeper learning of STEAM and Social Sciences \& Humanities (SSH). The adventures have paths for all grades of school, and it's designed also for open or flipped classroom. Unlike other games or virtual paths, which are carried out individually by each student/player, in this class game, every student must cooperate to reach goals.

The participants live a graphic adventure in which they face several choices of different paths with different opportunities. Furthermore, often the students must solve questions or must take some decisions to go on. As in classical role-playing games, players do not know where they are and the map of the location where they virtually move. Everything is revealed as players proceed: every choice during the game create a new original experience.

In GeoQuest, the players-students of a class also meet some mythological and historical figures along the way: they tell their story introducing the player in an atmosphere of mystery and dramas.

The myths and stories belong to the place and time in which the game is set, and these are correlated to the path the players will reconstruct.

While the path is revealed through the stories heard by mythological characters, players proceed and find some clues to discover a final event. The clues are based on scientific evidence, mineralogy, volcanology, geodynamics, history and myths [28]. To accustom students to interactivity in which there are skills of a different kind, through an apparent simplicity of the game and autonomous reworking, means that students get hard knowledge of the subjects studied, and they are making gradually accustomed to the work of continuous connection, in which knowledge is not divided into compartments, but blends harmoniously into a unprecedented unicum [20].

\subsubsection{Questions}

The questions are in the form of multiple choices, so players can proceed even without detailed knowledge of the matter. In this way the game facilitates the participation of all and avoids feelings of frustration related to prerequisites lacks. In addition, it can also be proposed at the beginning of a teaching module as engagement element.

Players respond individually, but the system proceeds according to the criterion of the majority, to demonstrate the collective responsibility (Fig. 4). At the same time each player can be evaluated by the system as one entity, regardless of the decision of the majority [18].

If the response of the majority is not correct, the system displays the error and the right answer, decrease the group points, but still continue the adventure, to not break the rhythm of the game and the students' attention.
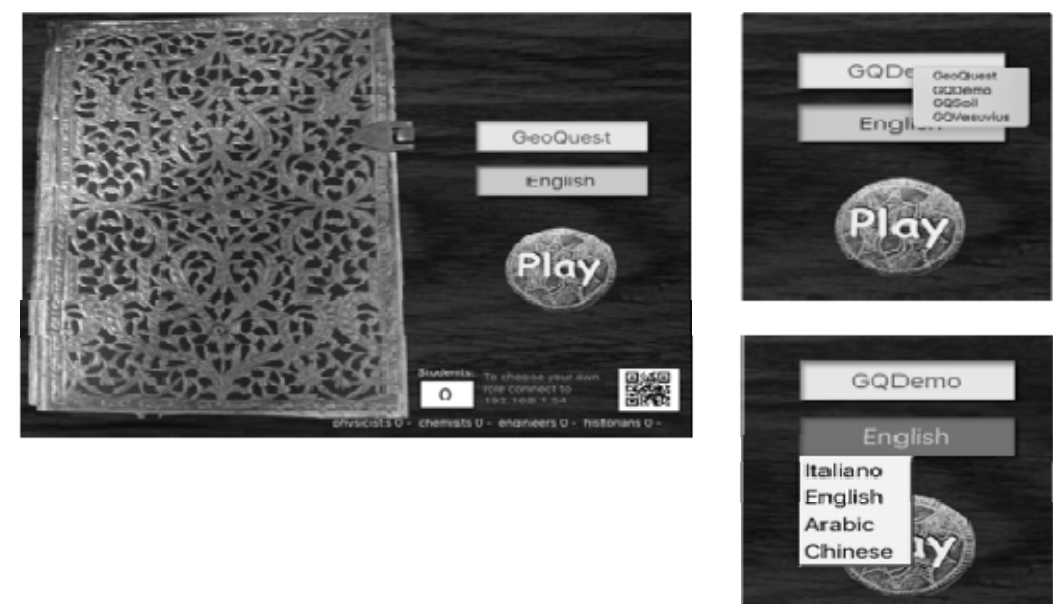

Fig. 3 Welcome Game screen. It's possible to choose the adventure path and the language. 


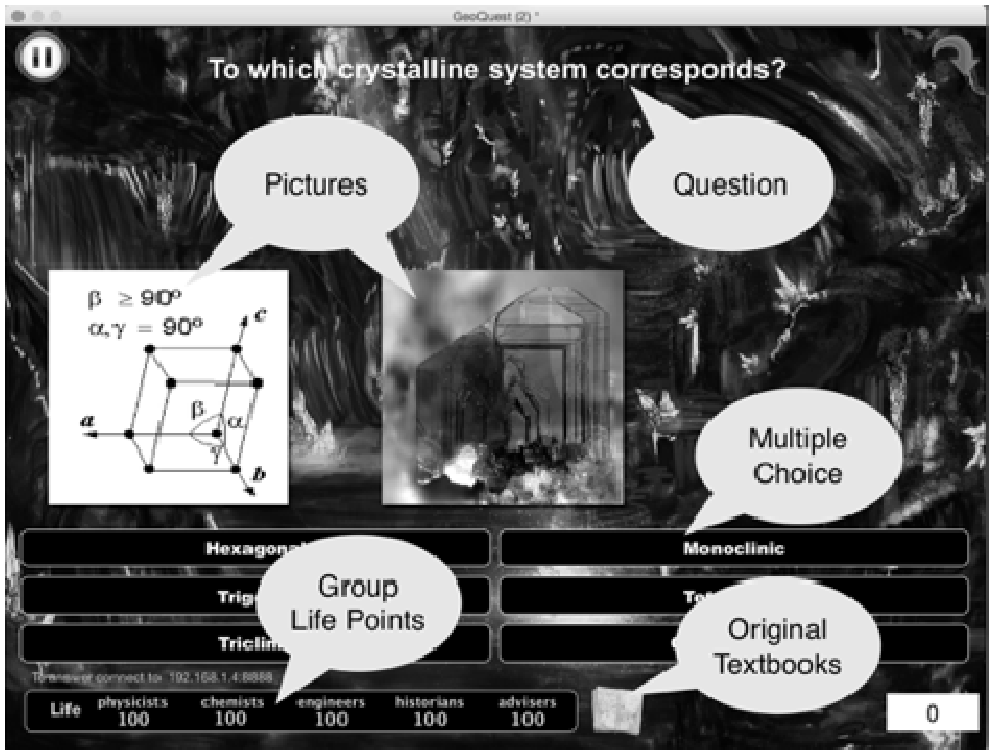

Fig. 4 A scientific question. Players respond individually, but the system proceeds according to the criterion of the majority, to demonstrate the collective responsibility.

\subsubsection{Game Aids}

Students have free access to materials that they found along the way, including original texts created on purpose, as notes about mineralogy, petrography, volcanology and others topics being in the different adventures.

Their consultation is easy and immediate since it's realized as synthetic PowerPoint presentations or PDF files full of icons, photos and pictures (Fig. 5).

\subsubsection{Technical Features}

Texts are spoken by a computer synthesised or human recorded voice in several different languages. Sound effects enhance the sensations during the gaming and there are several recited classic texts and original music tracks: this enhance the participation and diversify the communication codes to the students.

The players interact with the system using their own smartphones and tablets with a patented technology [29] which collects the individual answers. The system uses a Role Playing Game Engine (RPGE) [30] which controls the complete adventure and can enable the realisation of plenty of different adventures with small effort.

The game is controlled by a computer and it is followed by the whole class with an IWB or a simple projector (Fig. 6).

\subsubsection{Didactic Features}

It can be played in a laboratory to accomplish hands-on activities or in a classroom simulating workshop activities.

The teaching laboratory in fact must be understood as a methodology based on IBSE and Problem Solving together: it therefore does not require a real laboratory environment, but a workshop approach.

Roles. A recent survey [31] confirmed that those who dedicate themselves to role-playing games will be in general active consumers of cultural products often with good artistic skills with higher level of interest respect of their peers.

Any recreational activity has close relations with the pedagogy; there are no exceptions for this role playing game, even if with teenage users.

Moreno [32] experienced a successful group psychotherapy technique called "psychodrama", demonstrating that playing a "role", interpretation of characters with different characteristics, interaction with other characters; dynamic situations have high educational value.

In GeoQuest, students are divided into groups to give them special roles in scientific research and the system gives distinct scores to each group based on the "weight" question for the different roles played. 


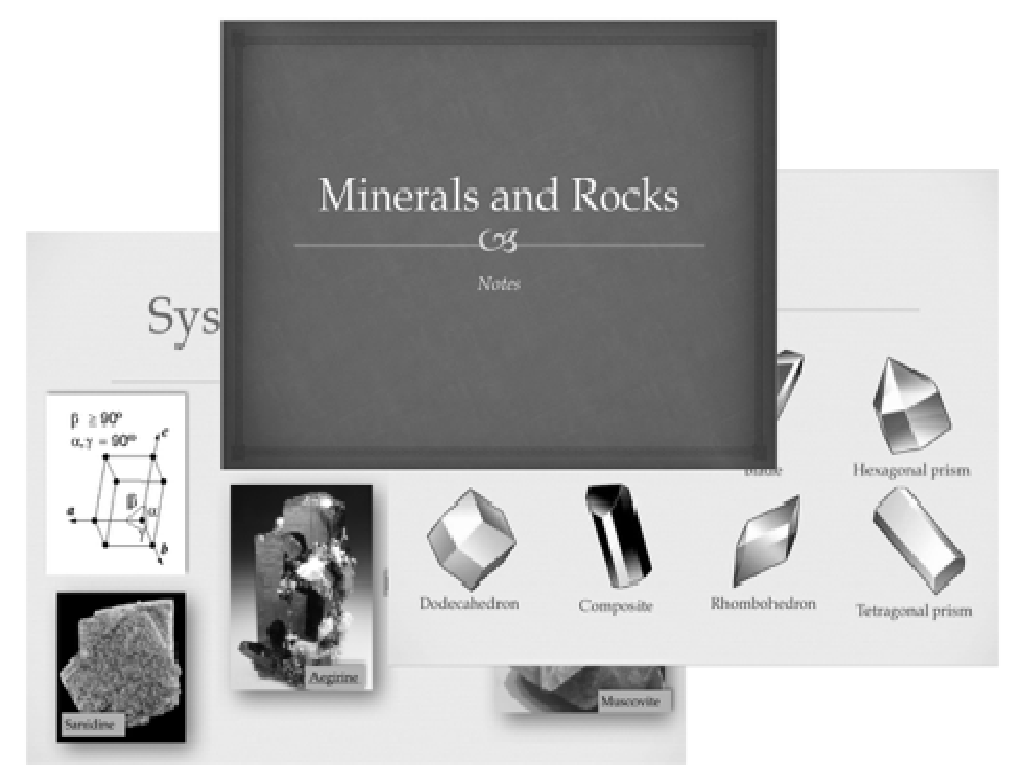

Fig. 5 A Game aid: the mineralogy book.

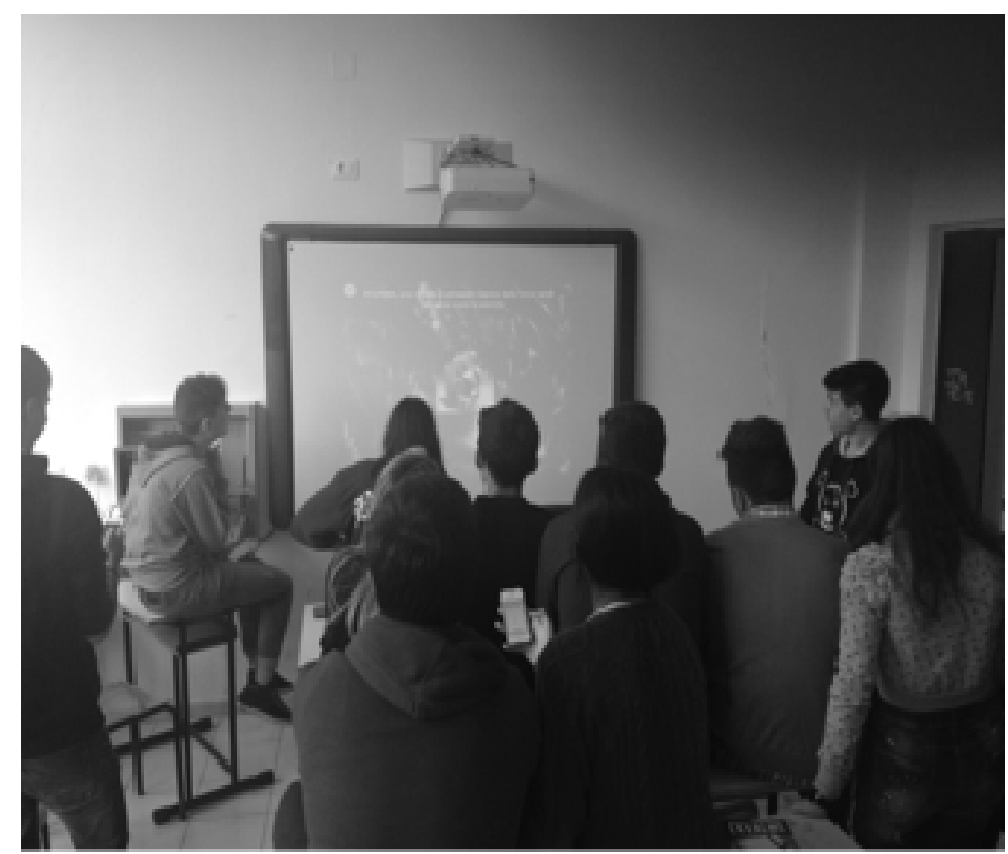

Fig. 6 The game can be followed by the whole class with a IWB (Interactive Whiteboard) or a projector.

Original texts. Most of the GeoQuest adventures present texts from literature that has to be interpreted: students must decode the right meaning to proceed successfully.

School failure or abandonments, in fact, seems to be related primarily to the inability in decoding written texts, than the difficulty in properly retrieving information in order to build skills.
With the international surveys which have highlighted the gaps in students' knowledge, skills and abilities, it was set up a proper definition of literacy: "reading literacy is understanding, using and reflecting on written texts, in order to achieve one's goals, to develop one's knowledge and potential and to participate insociety" [3]. Research has shown us that it is possible to repeat the text's content, even 
well, but that doesn't imply at all that a full absorption of the meaning happened and the true understanding of text has been acquired. At the base of a correct understanding of a text there is therefore the ability to build a semantic representation which must be coherent and well-formed [25, 26].

In the school practice, it is often given more importance to the elaborative inferences, necessary to personal interpretation [33], rather than the understanding of texts: students are encouraged to interpretive activities, where perhaps there are no requirements for punctual understanding. It is therefore necessary to encourage teachers and researchers to develop instructional strategies to foster these literacy skills.

\section{Results and Discussion}

The Game has been experimented in real conditions to have a scientific outcome of the innovative methodology and it has been experimented in several classes of different degrees.

The adventures paths used for the experimentation has been played in a laboratory environment (with real hands-on activities integrated into the adventures) and also in normal classrooms with simulating the hands-on activities showing a video.

\subsection{Experimental Methodology}

It seems essential to carry out an application that works on the pursuit of interdisciplinary teaching: all the latest publications in teaching emphasises the need of a multidisciplinary and multilingual approach. However there is a gap about how effectively you should realise this approach. It lacks operational and gnosiological guidance well structured to get it: how you can make an experimental research in education enlarged multi-disciplinary knowledge. About multidisciplinary modular routes accessible and usable even by the mostmodern multimedia platforms, research and experimental data are missing. Everything is entrusted to individual interventions, without a frame of theoretical and operational adequate treatment. In particular, when you intend to build ad hoc paths with the use of specific topics, there is a difficulty in the construction and processing of guidelines based on experimental research [34].

Everything collides with the framework provided by the leading international surveys which highlighted the dramatic lacking of textual competence of pupils [35] seen as wrong understanding of texts, regarding both humanistic and scientific topics. Therefore, this is the central point: carrying out research in the field of interdisciplinary teaching provides operational lines and a guide about the development of teaching units and structured pathways which contributes to the multidisciplinarity of the texts.

Currently, it necessitates a synergistic action aimed at developing innovative material that can support a theoretical research and the paradigm on how to practice and/or interdisciplinary teaching interventions.

\subsection{Types of Classrooms Involved}

Given the characteristics of the different game adventures, the trial could be performed into multiple types of classes:

1. Classes of primary schools;

2. Traditional classes of secondary schools;

3. Traditional classes of high schools (Scientific and Technical);

4. Traditional classes of high school with CLIL methodology, with the aim to:

- explore (the student makes virtual direct experience);

- process (the student deepens and strengthens the understanding of what $\mathrm{s} / \mathrm{he}$ has learned, applying it in new situations);

- evaluate (the student self-assess their understanding and skills acquired).

5. Flipped classrooms: as an instructional strategy and a type of blended learning that reverse the traditional educational arrangement by delivering 
instructional content, online, outside of the classroom [35]. It moves activities, including those that may have traditionally been considered homework, into the classroom. In a flipped classroom, students watch online lectures, collaborate in online discussions, or carry out research at home and engage in concepts in the classroom with the guidance of a mentor.

6. Open classrooms [36]: as student-centred classrooms design format which became popular in the United States in the 1970s. The idea of the open classroom was that a large group of students of varying skill levels would be in a single, large classroom with several teachers overseeing them. It is ultimately derived from the one-room schoolhouse, but sometimes expanded to include more than two hundred students in a single multi-age and multi-grade classroom. Rather than having one teacher lecture to the entire group at once, students are typically divided into different groups for each subject according to their skill level for that subject. The students then work in small groups to achieve their assigned goal. Teachers serve as both facilitators and instructors.

The experimentationstarted with:

- 5 classes secondary school 1st degree (age 12-13);

- 6 classrooms from secondary schools 2nd degree (age 14-18);

- 2 classrooms from high scientific schools (Lyceum);

- 2 classrooms from high technical schools;

- 2 flipped classrooms from high technical schools.

\subsection{Experimental Protocol}

The Experimental protocol foresees:

1. Questionnaire design and preparation;

2. Class experimentation;

3. Questionnaire execution (students and teachers);

4. Data Analysis.

The questionnaire has been prepared following criteria of brevity, readability and reliability.

After the first experimentation, the questionnaire has been improved to have more reliable results. The questionnaire design aims to:

- translate questions into concise and readable language;

- eliminate redundant or insignificant elements;

- ensure relevance to the data reported.

Student questionnaires will be designed to be delivered just at the end of playing each adventure and shall regard:

- Adventure's Educational Experience Evaluation;

- Comparison between Traditional and Innovative lessons;

- Immersive Experience Evaluation.

Teacher questionnaires will be designed to be delivered in the medium period, after adventure playing in their classrooms, and shall regard:

- Student Experience Evaluation;

- Comparison between Traditional and Innovative lessons Educational Outcomes by means of Adventure Experience;

- The numerical evaluation reflects an evaluation index between 1 and 10 .

The feedbacks not expressed numerically have been reported in numerical evaluations, using conversion grids between the number of positive factors and voting (i.e: predominantly negative factors $=$ less than 5; prevalence positive factors $=$ higher than 5 ).

The answers related to the same topic are reported as their average value.

Structure of the data processing. The data processing tables collect the same data for each class type, school type, etc. Graphic representations correspond to the types that at the best translate the trend of the data considered.

\subsection{Experimental Results}

A first very interesting result is highlighted by pie graphic representation of global average (Fig. 7) about didactic methodologies.

It's been considered in the evaluation participation, comprehension, ability to convey complex topics, ability foreign language learning. 


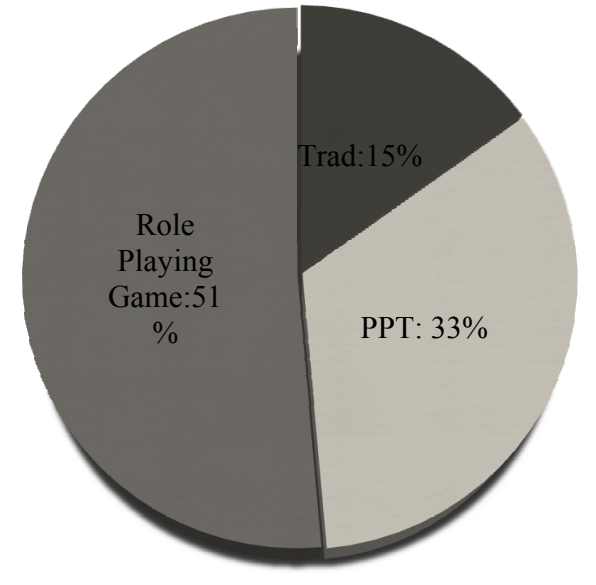

Fig. 7 Pie graphic representation of global average about didactic methodologies: RPG, the only interactive activity, exceed $50 \%$ of the satisfaction.

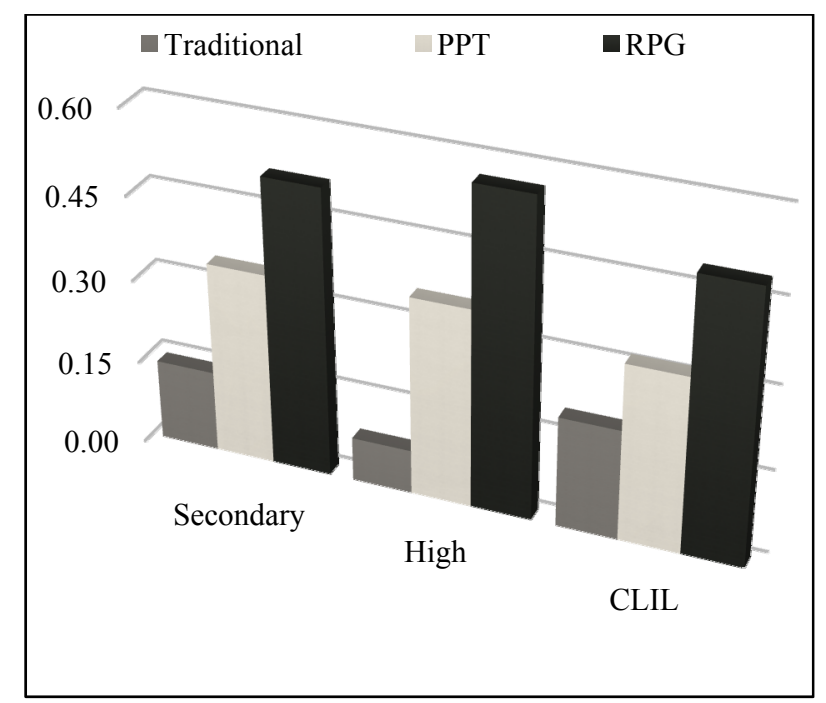

Fig. 8 Efficacy of interactive methodologies, also in case of CLIL methodologies (Content and Learning Integrated Learning), in respect to Traditional and PPT lessons and independently by the school degree.

Traditional lessons evaluation is at $15 \%$, PPT lessons evaluation is at $33 \%$ and Role Playing Game (RPG) evaluation is at $51 \%$. It is clear that lessons PPT in respect of normal frontal lessons are easier to follow by students, but in any case are frontal lessons.

Instead RPG, the only interactive activity, exceeds $50 \%$ of the satisfaction.

In Fig. 8, it is possible to highlight the efficacy of interactive methodologies, also in case of CLIL methodologies, in respect to Traditional and PPT lessons and independently by the school degree.
In this case, the game virtual voice, that speaks perfect British English in RPG, is the optimum to best gets the Communication in Foreign Languages skills [10].

The appreciation of RPG is in agreement with the experiments outcome (Fig. 9).

In the outcome, it is been considered the engage and improvement of science, history, foreign language knowledges and skills all together.

Prerequisites values are computed from the pupils' answers on some questions on their initial knowledge about the adventure involved disciplines.

The outcome is computed by the teacher evaluation on the results and interest on the same topics by the pupils a month after game playing. Compared to initial prerequisites, the results recorded are very satisfactory. In particular, if anyone can observe the same objects but distinguished by type of school (Fig. $10)$, it is possible to realise that the percentage results are much better where the prerequisites was lower (Technical schools).

\subsection{Teachers Satisfaction}

A first very interesting result is highlighted by pie graphic repTeachers need to improve their ICT skills and their mastering on interactive didactic applications (Fig. 11).

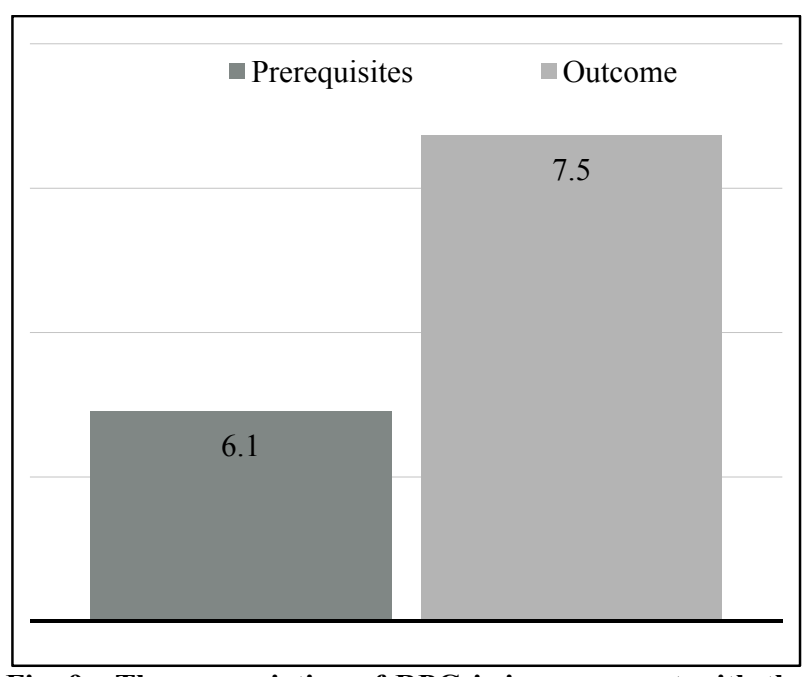

Fig. 9 The appreciation of RPG is in agreement with the experiments outcome. 


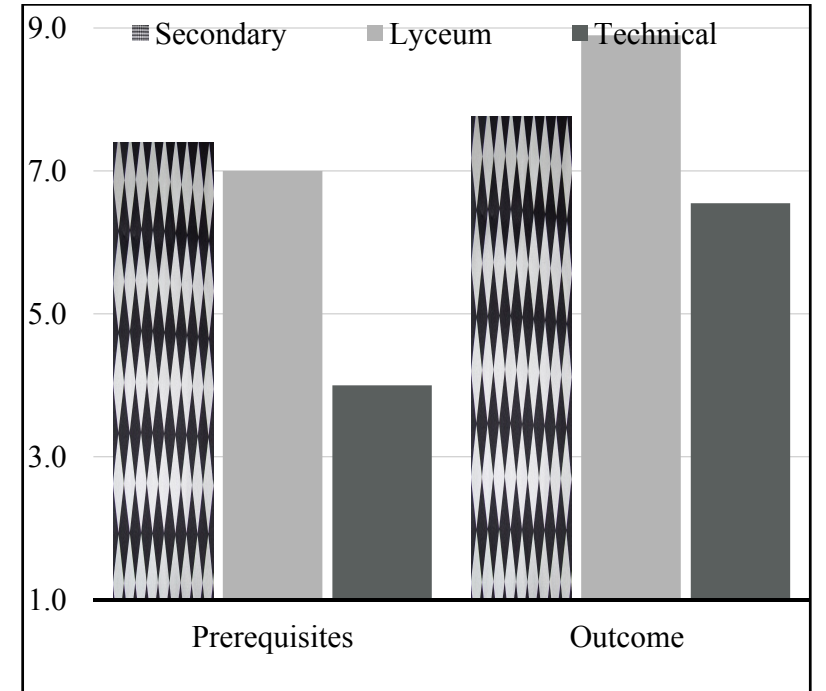

Fig. 10 If we can observe the same objects but distinguished by type of school (Fig. 10), we realise that the percentage results are much better where the prerequisites was lower (Technical schools).

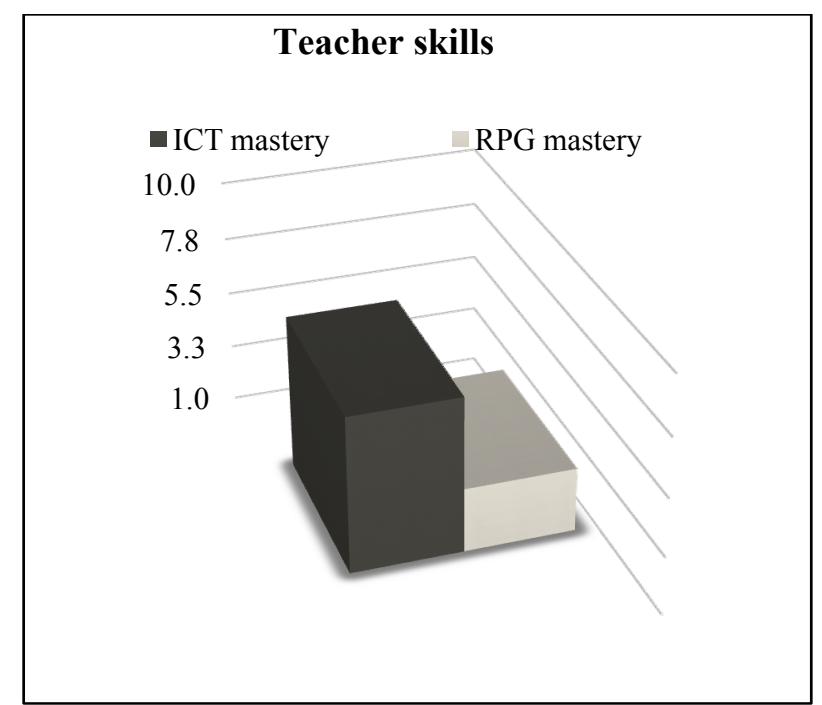

Fig. 11 Teachers need to improve their ICT skills and their mastering on interactive didactic applications.

They are also conscious that the actual availability of structured teaching materials is poor and unsatisfactory (Fig. 12).

This work experience get excellent feedbacks by teachers, in terms of efficacy of this new teaching methodology and of results achieving (Fig. 13).

\subsection{Computer Class Role Playing Game Satisfaction}

It is been asked students and teachers about some Game key characteristics, as interactivity, efficacy in understanding game rules and paths, class learning environment, RPG technical features and opportunity to use your device. Then it is been compared these characteristics with the Earth Science liking (darkest bar in Fig. 14).

It is evident that there is a clean-cut gap between the approval of school sciences disciplines and the evaluation of experience with GeoQuest Computer Class Role Playing Game.

Teachers' evaluations about Game features were more homogeneous: so they are been represented in

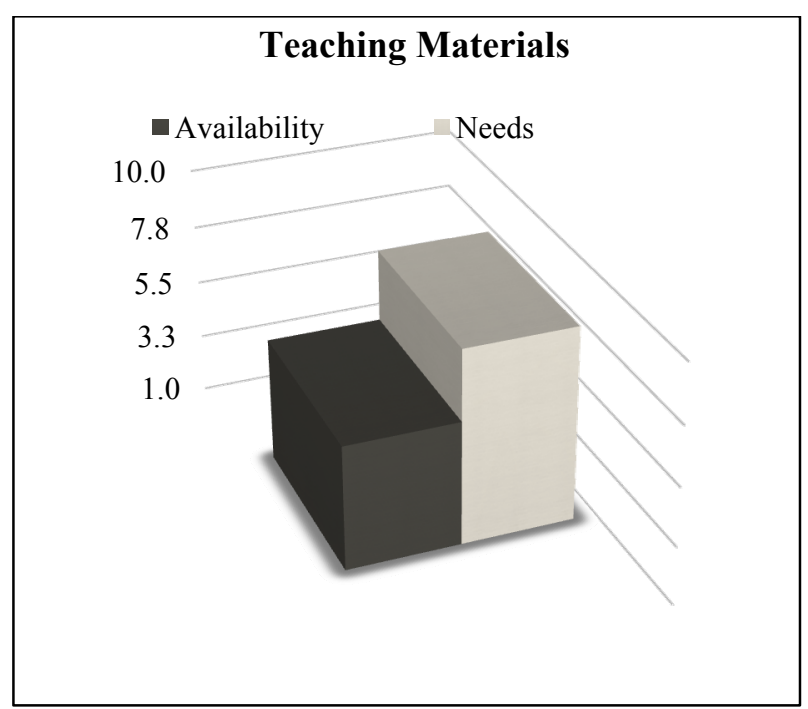

Fig. 12 Actual availability of structured teaching materials is poor and unsatisfactory.

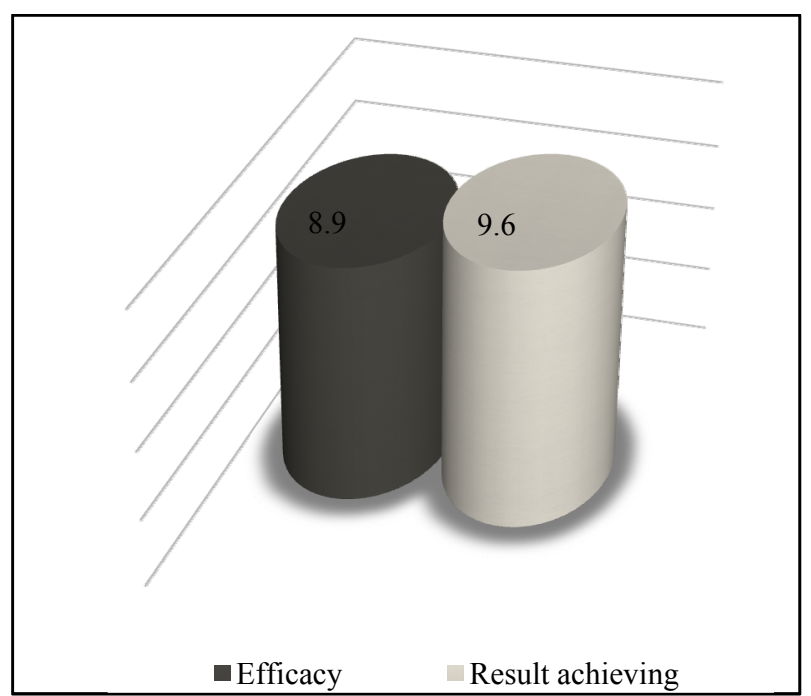

Fig. 13 Our work experience get, everywhere excellent feedbacks by teachers, in terms of efficacy of this new teaching methodology and of results achieving. 

Methodology to Foster STEAM Education

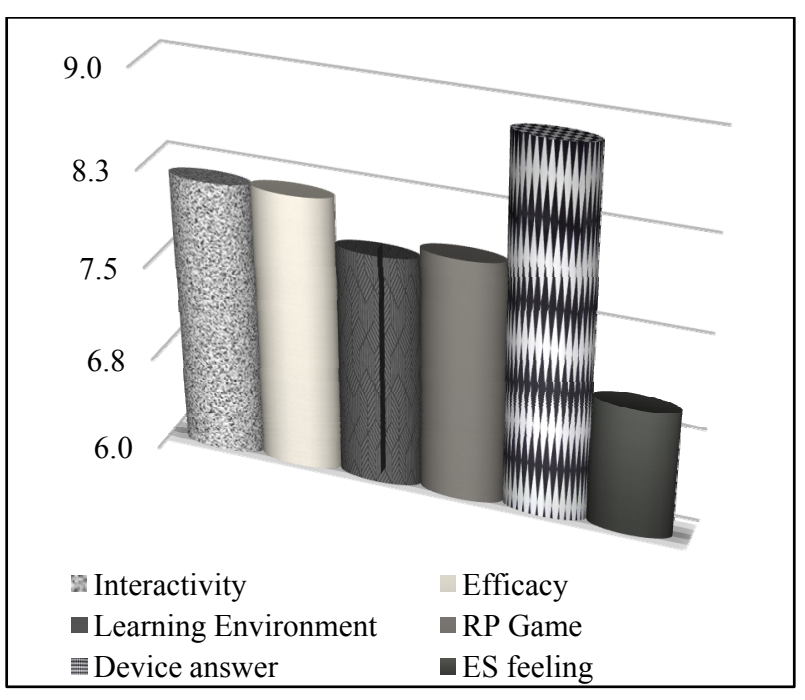

Fig. 14 There is a clean-cut gap between the approval of school sciences disciplines and the evaluation of experience with our Computer Class Role Playing Game.

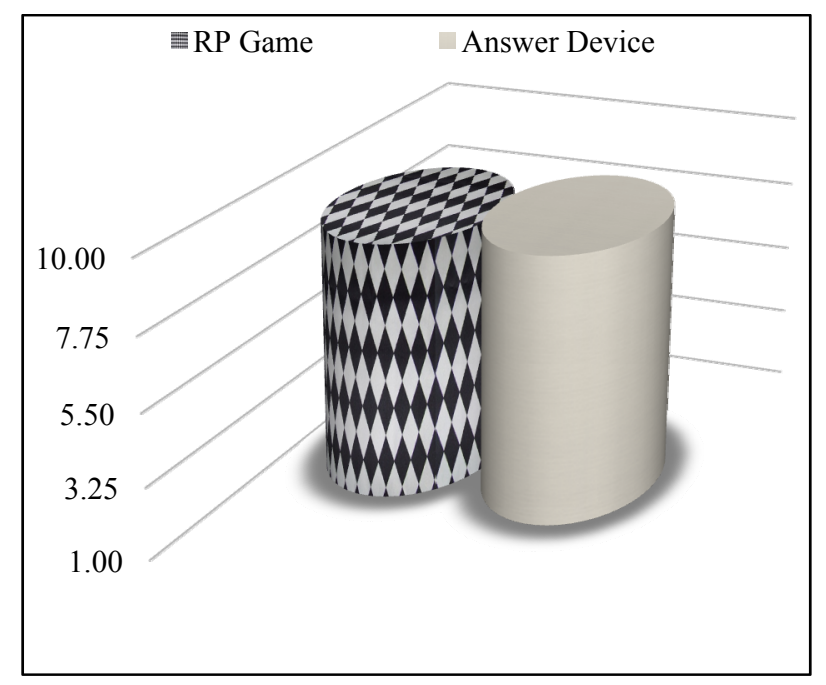

Fig. 15 Teachers evaluation about game features.

only one data (lozenge bar in Fig. 15) and compared with the excellent result for the answer device features.

\section{Conclusion}

GeoQuest Project improves the innovation and creative capacities of learners and supporting the new role of teacher as a learner coach.

It responds to European instances about education (encouraging people to learn study and update their skills, research/innovation (creating new products/services), digital society (using information and communication technologies). Therefore adventures game paths is compatible with European recommendations about the awareness of the environmental risks [11] enhancing the study of Earth Sciences. This Computer Class Game really exploits the potential of ICT, with the bottom-up approach and it ensures the benefits of Inquiry Based Science learning without burdening the load work of teachers.

It leverages the latest achievements in the field of information technology, which allow overcoming the loneliness of the subject in learning, weakness inherent in the use of the virtual games and computer games. The game meant as a teaching tool is situations-learning modes that require the student to mobilise its resources to find solutions, in which the problematic natures of proposed tasks require to be connected to their significance.

The use of educational game allows task performance related to different fields of knowledge, useful to re-read the highlighted characters in relation to [18]:

- ask students to recover their previous knowledge;

- encourage the use of complex cognitive processes (reasoning, transfer, critical thinking, creative thinking);

- be inserted into meaningful and real contexts;

- stimulate students' interest;

- be open to solving different paths;

- challenge students' the ability.

- Experimental results [34] were outstanding and prove the achievement of these goals:

- New games development and new teaching methods;

- Earth Sciences strengthening into science education.

Teaching of the last generation ICT increase.

Support to the teacher, through the use of teaching materials updated to the latest standards andmethodologies.

CLIL Teaching support, allowing teaching materials in any language. 
Personalised teaching support also in case of Special Educational Needs (SEN), best for a complete inclusion.

Spreading a truly interdisciplinary training culture, exceeding the dichotomy STEAM and SSH.

\section{References}

[1] Eurobarometer Standard. 2005. Public Opinion in the European Union.

[2] Eurobarometer Standard. 2010. Public Opinion in the European Union.

[3] OECD. 2006. Programme for International Student Assessment-INVALSI 2006.

[4] OECD. 2009. Programme for International Student Assessment-INVALSI 2009.

[5] Rocard, M. 2007. "Science Education Now: A Renewed Pedagogy for the Future of Europe." European Commission.

[6] Scapellato, B. 2014. "A Pilot Training Course to Take IBSE Approach in Earth Science Teaching in Italian Secondary Schools: Analysis of Teachers' Perceptions." Ph.D. thesis, University of Camerino.

[7] Venturini, C. 2009. "Scienze della Terra nella scuola superiore: appassionare gli studenti è davvero un'impresa disperata?" New Trends in Science and Technology Education 1: 77-96.

[8] Occhipinti, S. 2014. "Models and Guidelines for More Effective Tools and Paths in an Active Teaching-Learning in Earth Sciences: Looking for a Unifying Principle." Ph.D. thesis, University of Camerino.

[9] Euridyce. 2006. "Science Teaching in School in Europe: Policies and Research." Brussels.

[10] European Commission. 2006. "Key Competences for Lifelong Learning." Recommendation 2006/962/CE.

[11] European Commission. 2010. "HORIZON 2020-The EU Framework Programme for Research and Innovation." Accessed December 2016. http://ec.europa.eu.

[12] VV. AA. 2007. "Presentation of the Working Group Document for the Development of Scientific and Technological Culture.” 1: 1-2.

[13] OECD. 2015. Programme for International Student Assessment-INVALSI 2015.

[14] Realdon, G., Paris, E., and Invernizzi, M. C. 2013. "Teaching Earth Sciences in Italian liceo High School following the 2010 Reform: a Survey." Rend. Online Soc. Geol. It. 40: 71-79.

[15] Avvisati, F., Hennessy, S., Kozma, R. B., and Vincent-Lancrib, S. 2013. "Review of the Italian Strategy for Digital Schools.” OECD Education Working Papers
90, OECD Publishing.

[16] Marini, G. 2016. "La comunicazione nell'apprendimento" Bibienne Blog il Accessed December 2016. http://rsdidattica.blogspot.it/2016/05/gianfranco-marini-la -comunicazione.html.

[17] De Benedetti M. 1998. "Personalizzazione e apprendimento." In ProgettoOrientamento. La formazione orientativa, Ministero della Pubblica Istruzione.

[18] Maraffi, S., and Marinelli, A. 2016. "VALUQuest a Role Playing Game for Skills Assessment." In Proceedings of the Hawaii University International Conferences on Science, Technology \& Engineering, Arts, Mathematics and Education (STEAM), USA.

[19] Mori, L. 2012. "Simulation and Serious Games as Education Tools." Research in Hermeneutics, phenomenology and practical Philosophy, Vol.IV No.1 June 2012, 56-72 ISSN 2067-3655.

[20] Maraffi, S., Sacerdoti, F. M., and Scamardella, A. 2016. “GeoQuest VESUVIUS a Class Role Playing Game." In Proceedings of the Hawaii University International Conferences on Science, Technology \& Engineering, Arts, Mathematics and Education (STEAM), USA.

[21] Bisanti, M., and Ligabue, A. 2015. "Il Gioco di Ruolo come Strumento Didattico." Associazione PlayRes, Modena. Accessed December 2016. http://www.ludologo.com/wp-content/uploads/2012/09/G iocoRuolo.pdf.

[22] Greenfield, P. M. 1995. Mente e media. Gli effetti della televisione, dei computer e dei videogiochi sui bambini. Armando.

[23] Trinchero, R. 2015. "Il gioco computerizzato per il potenziamento cognitivo e la promozione del successo scolastico. Un approccio evidence based."Form@re, Open Journal on Online Education 14 (3): 7.

[24] Zini M. Rete e gioco. 2014. "Ambiente per apprendere il complesso in modo autonomo.” EL.LE 3 (1): 2280-6792.

[25] Kintsch, W. 1998. Comprehension: A Paradigm for Cognition." Cambridge: Cambridge University Press.

[26] Levorato, M. C. 1988. Racconti, storie, narrazioni. Bologna: Il Mulino.

[27] Padovani, R. 2006. La comprensione del testo scritto in età scolare. Una rassegna sullo sviluppo normale e atipico. Psicologia clinica dello sviluppo 10 (3): 369-398.

[28] Maraffi, S., and Scamardella, A. 2016. "GeoQuest VESUVIUS an Interdisciplinary Role Playing Game." In Proceedings of the International Conference New Perspectives in Science Education, 342-346.

[29] Sacerdoti, F.M. 2013. "Autonomous System to Use Web Educational Contents in a Classroom." Italian Patent IT0001422138.

[30] Maraffi, S., and Sacerdoti, F. M. 2015. "EVO-RPGE an 
Methodology to Foster STEAM Education

Interactive Role Playing Engine." In Proceedings of ICEILT International Congress on Education, Innovation and Learning Technologies, p. 148.

[31] Areni, A., and Giuliani, L. 2015. "La nascita del gioco di ruolo, la sua importanza nella formazione dell'individuo ed il suo grande valore educativo Survey." Sociology at University La Sapienza-Rome.

[32] Moreno, Z. T., Blomkvist, L. D., and Rützel, T. 2000. Psychodrama, Surplus Reality, and The art of Healing. London: Routledge-Taylor \& Francis.

[33] Graesser, A. C., Singer, M., and Trabasso, T. 1994. "Constructing Inferences during Narrative Text
Comprehension." Psychogical Review 101 (3): 371-395.

[34] Maraffi, S., and Sacerdoti, F. M. 2016. "GeoQuest a Computer Classroom Role Playing Engine to Teach Earth Science in an Interdisciplinary way." In Proceedings of 9th Annual International Conference of Education, Research and Innovation, 6119-6127.

[35] Evers, F. T., Rush, J. C., and Berdrow, I. 1998. "The Bases of Competence: Skills for Lifelong Learning and Employability." San Francisco.

[36] Cuban. L. 2004. The Open Classroom, on Education Next vol.4 n.2, Springer, Online article. Accessed December 2016. http://educationnext.org/theopenclassroom/. 